\title{
A Study on Cultural Urban Regeneration Using Modern Industrial Resources: Focusing on the Site-Specific Cultural Places of Gunsan, South Korea
}

\author{
Hokyung Chung and Jongoh Lee *D \\ Department of Global Culture and Contents, Hankuk University of Foreign Studies, 107 Imun-ro, \\ Dongdaemun-gu, Seoul 02450, Korea; sonicbath@hufs.ac.kr \\ * Correspondence: santon@hufs.ac.kr; Tel.: +82-10-3368-3760
}

Citation: Chung, H.; Lee, J. A Study on Cultural Urban Regeneration Using Modern Industrial Resources: Focusing on the Site-Specific Cultural Places of Gunsan, South Korea. Land 2021, 10, 1184. https://doi.org/ 10.3390/land10111184

Academic Editors: Manuel Duarte Pinheiro and Miguel Amado

Received: 28 September 2021

Accepted: 1 November 2021

Published: 4 November 2021

Publisher's Note: MDPI stays neutral with regard to jurisdictional claims in published maps and institutional affiliations.

Copyright: (c) 2021 by the authors. Licensee MDPI, Basel, Switzerland. This article is an open access article distributed under the terms and conditions of the Creative Commons Attribution (CC BY) license (https:// creativecommons.org/licenses/by/ $4.0 /)$.
Abstract: Gunsan is a port city located on the west coast of South Korea. After the port was opened in 1899 , foreign concessions were formed there, and the modern city began to be formed in accordance with Japanese colonial policy. This region grew into a modern port city by exporting rice harvested from the plains in the hinterland to Japan and managed and controlled commercial and industrial products of the surrounding area. Modern industrial facilities such as warehouses, financial, and administration facilities necessary for seizing the food resources for the colony were built there, and Gunsan developed as a hub city in the southwestern region of South Korea during the 1930s. However, after liberation in 1945, the number of modern industrial facilities in this area, which contained traces of Japanese imperialism, gradually declined. In the 2000s, as urbanisation accelerated, the problem of abandoned modern industrial facilities was raised, and the necessity of urban regeneration by utilizing the modern industrial facilities scattered in the original downtown of Gunsan emerged. The purpose of this paper is to examine the regional activation and cultural regeneration of the city by using modern industrial facilities as cultural places and targeting the case of Gunsan, which was developed as a colonial-planned city. In particular, through field studies, this paper examines those cultural spaces, utilising modern industrial facilities that contribute to the formation of regional uniqueness, mediate local communities, and create future values of sustainable cultural regeneration.

Keywords: Gunsan; site-specificity; cultural place; sustainable cultural regeneration; modern industrial heritage; cultural mediation

\section{Introduction}

\subsection{Background and Purpose}

With globalisation and de-industrialisation accelerating, each city's unique regional characteristics and cultural competitiveness are emphasised. This perspective originated from reflecting on urban development in the mid- to late 20th century, when regional characteristics, the uniqueness of places, and local communities were destroyed as the history and culture of the area were damaged due to the focus on revitalisation through physical expansion and the sprawl of the city. This paper considers the cultural resources of the city, including regional specificity and historical identity, important factors leading to sustainable urban regeneration by deviating from the development-oriented perspective in urban regeneration plans. Moreover, this discussion focuses on Gunsan, which was established as a modern port city following the opening of ports in the late 19th and early 20th centuries.

Gunsan is a port city located on the west coast of South Korea. After the opening of the port in 1899, it began to assume the form of a modern city based on Japan's colonial policy. It grew into a modern port city by exporting rice gathered from the granaries in the hinterland to Japan and managing and controlling the industrial products of neighbouring cities. As modern industrial facilities, such as warehouses, and centres for finance and 
administration, were built here for colonial food resource exploitation, it grew into a hub city in the southwestern region of South Korea, but after liberation in 1945, modern industrial facilities bearing traces of Japanese imperialism and exploitation gradually declined.

In the 2000s, urbanisation accelerated and the problems of abandoned modern industrial facilities were raised. The need for urban regeneration using the modern industrial heritages scattered in the original downtown from the first half of the 20th century emerged. This paper aims to examine how abandoned industrial facilities can be used for cultural and creative place-making in Gunsan, formerly known as a colonial planned city. Not enough attention has been paid to the cultural forces that enhance urban regeneration in South Korea. This paper pays particular attention to the modern industrial facilities that recollect colonial history and experiences as unique historical and cultural resources of the region and examines ways in which local residents can overcome the historical memories of the past and these industrial facilities can revitalise new local culture and increase future value.

\subsection{Methodology}

In order to break away from the development-oriented perspective and examine regional specificity, historical identity, and new cultural value, this paper investigates and analyses ways to utilise modern industrial heritages, and we would like to present cultural and humanistic values and perspectives for sustainable urban regeneration. For analysis, Gunsan was selected as the target site for a case study in which the city's creative values and regional characteristics were utilised, and theoretical and field studies were conducted on it. Throughout this study, we examine the original context in which the modern city was established and determine the old and decaying factors that made up the city according to historical vicissitudes. Then we discuss strategies for revitalising the city sustainably.

This paper analyzes the process of utilising industrial heritage in Gunsan based on the case study methodology and surveys its usage as a cultural space in the decaying old downtown. As well as the survey and an accompanying literature review, basic interviews with local regeneration experts in Gunsan for field research are carried out, along with visits to the target sites.

As a result of the case analysis, it was found that most of the modern major industrial facilities are used as cultural facilities and as a way for visitors to experience and become educated on the history and culture of Gunsan. The urban regeneration strategy in which Gunsan's historical and regional specificity was presented in the cultural context was being implemented intensively. This regeneration strategy transformed the old city centre into a historical and cultural district using the subsidy from the central government and contributed to creating a new urban image of Gunsan as a modern cultural city.

This paper examines the cultural value of modern industrial heritage that has been lost or dismantled because of urban development, focusing on 'regeneration based on the original'. In addition, it diagnosed that the totality of historical memories and traces remaining in urban spaces can become an urban heritage [1]. Traditional buildings and cultural assets that possess clear preservation value from a historical and cultural perspective were legally entitled to protection and preservation, but in many cases, modern industrial heritage buildings from around the 20th century disappeared (or were dismantled) in the aftermath of urban development.

In the case of Gunsan, many modern buildings built during the colonial period since the opening of the port remained in the old city region until the 1990s. However, many of them were then demolished, mainly by civic groups, as these buildings were considered to symbolise the colonial era and the history of exploitation [2]. Modern buildings, which were damaged in large numbers, as they were perceived as a remnant of colonisation and became subject to demolition during urban development, were perceived to have new cultural values. This change in perception began in 2001 when the Cultural Heritage Administration introduced the 'registered cultural property' system for modern heritage [3]. Moreover, this change in perception provided a meaningful foundation that following the 
expansion of the city that occurred from the perspective of development during the high growth period of the 1970s and 1980s, as the decrepit old downtown and the abandoned modern buildings close to the residential area within the old city were converted into cultural resources. As a result, Gunsan is in the midst of a transitional period while creating a new urban culture.

Meanwhile, international interest in the concept and value of industrial heritage was sparked around the time this situation unfolded in South Korea. The 'Nizhny Tagil Charter for Industrial Heritage', proposed by the International Conference on the Conservation of Industrial Heritage (TICCIH) in 2003, is a representative case. In this field, industrial heritage is defined as a heritage of industrial culture with historical, technological, social, architectural, or scientific value. Industrial heritage includes places used in social activities related to industry, such as buildings, machines, workshops, factories, mills, sites for mines, and other processing activities, warehouses, shops, and locations for energy production and transmission that are utilised for transportation and infrastructure, housing, religious facilities, and education [4].

This paper focuses on the process of restoring and utilising the modern industrial heritages in the old city region of Gunsan while meeting these international standards. Furthermore, the industrial heritage in the old city region of Gunsan has been considered lifestyle-related heritage, which, along with the history of urban change from the establishment of the modern city, has formed the unique characteristics and identity of the region in the lives of local residents; the cultural regeneration of this sustainable city is discussed in the paper.

The paper specifically explores site-specific resources that form a unique local culture as the modern industrial heritage of Gunsan, which is the target site. The paper presents the meaningful perspective that the use of this heritage contributes to the restoration of the placeness of the region and the formation of regional identity, promotes the participation and strengthening of local communities, and encourages the sustainable regeneration of the decaying original city centre.

\section{Theoretical Framework}

\subsection{Cultural Regeneration using Modern Industrial Heritage}

With the acceleration of urbanisation due to industrialisation, the development of modern cities is a global phenomenon. In the west, physical environment improvement through urban reconstruction was introduced in the 1950s. After urban revitalisation in the 1960s, urban renewal in the 1970s and urban redevelopment in the 1980s have been discussed [5].

There are several notable discussions of cultural and creative city theory. Landry is one of the first theorists to discuss the creativity of urban regeneration. According to him, creativity is a core strategy for dealing with various urban problems, such as urban poverty, education, aging, land use, information technology, bureaucracy, leadership, environmental issues, and cultural activities [6]. Meanwhile, Florida explored how creativity has become an important factor in urban development. He suggested that the "Creative Class" produces significant innovation and diversity and tolerance in the city [7].

A movement which emerged in the 1970s and 1980s encouraged the utilisation of cultural facilities and later cultural quarters and districts, which extended to cultural clusters. Mommaas explored how the formation of cultural clusters turned into a new, alternative source for urban cultural development. Whereas Landry focused on high culture, such as the arts and occasionally folkway and customs in the creative city, Mommaas discussed mixtures of cultural functions and activities, from production to presentation and consumption in the cultural clusters [8].

Urban change, that is, urban growth and decline, is in fact intertwined with the progress of capitalism, the dynamic pursuit of accumulation, and socio-economic changes that result in spatial ramifications of growth and dislocation. The process of urban change and regeneration enabled a new exploration of the city as it was associated with social, 
political and economic fluctuations [9]. The city reinforces its identity as a new issue of urban regeneration and represents an important activity for regional development. Cities, places and destinations are associated with locality, along with their artistic characteristics as place-making. Cultural regeneration as material and immaterial, tangible and intangible heritage produced over time in different cultural and socio-political contexts appears to be highly valuable in the context of urban regeneration [10].

The globalisation and restructuring of the economy have increased the economic, social, and physical problems faced by many regions, and there is thus more consideration of various factors that affect urban regeneration and local cultural activities. Evans reviewed three models of cultural contribution to urban regeneration. He identified three models through which cultural resources are incorporated into the regeneration process. The three models are as follows [11,12]:

- Culture-led Regeneration: 'Cultural activity is seen as the catalyst and engine of regeneration. The activity is likely to have a high-public profile and frequently to be cited as the sign of regeneration. The activity might be the design and construction (or re-use) of a building or buildings for public or business use' (e.g., Tate Modern); 'the reclamation of open space' (e.g., the garden festivals of the 1980s and 1990s in Gateshead, Liverpool, etc.); 'or the introduction of a programme of activity which is then used to rebrand a place'.

- Cultural Regeneration: 'Cultural activity is fully integrated into an area strategy alongside other activities in the environmental, social and economic sphere. Examples include Birmingham's Renaissance where the arts were incorporated with policy, planning and resourcing through the city council's joint Arts, Employment and Economic Development Committee, and in the "exemplar" cultural city, Barcelona. This model is closely allied to the "cultural planning" approach to cultural policy and city regeneration'.

- Culture and Regeneration: 'Cultural activity is not fully integrated at the strategic development or master planning stage. The intervention is often small-scale: a public art programme for a business park, once the buildings have been designed; a heritage interpretation or local history museum tucked away in the corner of a reclaimed industrial site. In some cases, where no planned provision has been made, residents and cultural organizations may respond to the vacuum and make their own interventions-lobbying for a library, commissioning artists to make signs or street furniture, recording the history of their area, setting up a regular music night, etc. Although introduced at a later stage, cultural interventions can make an impact on the regeneration process, enhancing the facilities and services that were initially planned'.

In the case of South Korea, urbanisation for national reconstruction and urban development by period occurred compressively after the colonial period and the Korean War in the first half of the 20th century. It is no exaggeration to say that Korea's urbanisation process transformed Korean society from a rural society to an urban one. Liberation in 1945 was immediately followed by its rapid increase in the urbanisation rate from $13 \%$ to $24.5 \%$ in $1955,39.1 \%$ in $1960,50.1 \%$ in 1970 , and $89 \%$ in 2000 [13]. This history of urban expansion caused various problems, such as the levelling of regional specificity, deindividuation of regional historicity and identity, and destruction of communities. Cultural and humanistic reflection and discussions on sustainability are being increasingly required in urban development.

Regarding the discussion of sustainability in urbanisation, the UN launched the World Commission on Environment and Development in 1987, and this commission has provided basic directions for sustainable development. The notion of sustainability was commonly provided by the Brundtland Report, which defined it as 'development that meets the needs of the present without compromising the ability of future generations to meet their own needs' [14]. This created some possibilities of connecting environmental consideration to regional development. Moreover, it provided motivation for subsequent international 
agreements and gave a basis for sharing economic, social, and environmental awareness regarding development.

The modern industrial remains of the Gunsan region addressed in this paper include ports, factories, warehouses, transportation and other industrial infrastructure built during the colonial period, which was a period of political and social turbulence in Korea that started in the end of the 19th century and lasted until the first half of the 20th century. Because these remains possess historical traces and memories of the disgrace of the Japanese colonial period, they were neglected and many of them disappeared, as they were downplayed as representing the past that Koreans wanted to forget and the era that they had to overcome. The devastation of the modern industrial heritages has become a symbol of urban decline, along with the aging and decline of the old city centre.

The cultural regeneration approach, which grafts cultural resources into industrially declining areas, enables the functioning of the devastated industrial heritage in the city as a new cultural resource with regional originality and cultural specificity. As the city's historicity, locality, and identity, which were overlooked by the regeneration method centred on physical facilities, are strengthened, it will become possible to present a direction for sustainable urban revitalisation.

\subsection{Placeness for Sustainable City Planning}

Rogers has mentioned that cultural heritage can include urban resources, and that cities with historical heritage require a comprehensive change in perception in terms of the existing concept of conservation. Specifically, the objects that truly need to be preserved in cultural heritage do not refer to only architectural objects with tangible physical entities; they encompass various elements. This has a deeper connection with the local culture [15]. To determine these various cultural elements, this study will discuss historical, social, and meaningful places that people attach to.

Space is generally seen as a more abstract phenomenon. Place, in contrast, is commonly understood as a bounded form of space that has concrete physical features, is shaped by human experience and imbued with meaning. Places tend to have concrete material characteristics, for instance, in the form of architecture or natural features. Place has often been associated with rootedness, authenticity, and the 'local' [16]. Furthermore, attachment to a specific place in the region and experience with it form an 'identity of places'. This process creates a deep sense of solidarity as people share an identity based on a particular region, and it becomes an essential element in creating a culture and landscape unique to the region.

However, a uniform and standardised landscape has been created, which can lead to so-called placelessness, as places are deprived of their individuality in the process of commercial development, and standardised and uniform urban development. Furthermore, cultural elements and landscape characteristics unique to a specific region or place disappear, or the historical meaning of a place disappears [17]. As the placeless uniformity significantly reduces awareness and understanding of the cultural meaning and historical identity of a place, attachment towards the place or its authenticity reduces and ultimately, the authenticity of the local culture fades.

Mass communication, increased mobility, and the merging of consumer societies are rapidly accelerating homogenisation worldwide, and cities filled with ubiquitous places provide the same experience anywhere on the planet. Fast food restaurants, shopping malls, downtown shops, and hotels are homogeneous, and nothing characteristic about a particular locality remains. As regions with strong placelessness have other-oriented characteristics centred on outsiders, consumers, and tourists rather than local residents, they became a major cause of the sudden disintegration of the community.

Urban redevelopment, moreover, has removed the poorest residents from central quarters to the distant edges of the metropolitan region, replacing them with tall office towers, luxury housing, and large-scale cultural amenities. This 'upscaling' has provided the visual images and programmatic narrative for a nearly universal rhetoric of growth 
in the region. Urban redevelopment carried out in this way does not simply mean a new change of urban space but also a change in the cultural and special character of the original place. Zukin proposes the idea of authenticity, primordial rootedness in place and time to support urban cultural diversity. According to her, as an analytic notion, authenticity has several virtues: it directs attention to culture in the city development, connects to the search for sources of real identity, and reflects concern with maintaining the historical attachments of place [18].

Jacobs described cities on the threshold of the momentous changes reflected on a way of physical urban landscape. Most of all, Jacobs suggested an ideal to which city dwellers and the urban villages aspired. She interpreted societal progress as similar to ecological development and suggested that a city's vernacular features are complex, resilient, and creative, like nature's ecosystems. Jacobs provided a unique insight into places within the city, such as the street as an important factor for city safety, social cohesion, and economic development. In addition, according to her, the neighbourhood space was identified as the core place that created the vitality of the city [19].

Hence, sustainable urban regeneration presupposes a uniform and homogeneous process of urbanisation and aims for the restoration of the meaning, history, identity, and authenticity of places that were excluded from regional development. Interest in discovering and utilising site-specific resources that have regional specificity has been growing. A good example of this is the restoration of placeness through art and culture, and a series of efforts to restore the culture of the local community have been made with the concept of 'site-specific art' since 1970. It is not a uniform and short-term event-oriented art activity but an alternative activity based on community-specific and continuous projects that emphasises various contexts [20].

\section{From Industrialisation to Cultural Regeneration: The Case of Gunsan}

\subsection{Background and Process of Modern City Formation and Urban Decline}

As independent regional development was undertaken according to the wishes of the residents of the treaty country after the Treaty of Protection between Korea and Japan was adopted in 1876, ports were established in Busan, Wonsan, and Incheon, settlements for foreigners were established, and modern cities were actively built in Korea. Modern facilities such as banks, post offices, and schools were built in these open-port cities. A railroad connecting other regions and ports was opened, and a modern road network was maintained. Accordingly, the open-port city took on the role of a modern distribution centre and the function of an early industrial city rather than an administrative function; thus it had distinctive characteristics that differentiated it from the Korean traditional towns [21].

Gunsan has been mentioned as a candidate site for port opening since 1897. The commercial area that was formed around the Geumgang River and the Gimje and Mangyeong Plains, the largest rice producers in Korea, are the hinterland. It was easy to build an overseas trading port in this area because it faces the sea. As the ease of exporting rice to Japan from here was highlighted, Gunsan was opened in 1899, and a residence for foreigners was established. It developed into a colony base area, as the area facing the port was intensively urbanised in response to the needs of Japan, which was its largest trading partner. In the so-called foreign settlement, related facilities such as government offices, customs, and banks were built because of population growth and urban expansion. The composition of the population had a multinational aspect. During the early days of port opening, the plan of the general foreign settlement in Gunsan and the status of residential construction can be seen in Figures 1 and 2.

In Gunsan's foreign settlement, which was formed in a grid pattern, there was a small number of Chinese residents, but the majority were Japanese. Accordingly, only the Japanese consulate was established as a foreign embassy in charge of related affairs, and the city was effectively under the influence of Japan from the early days of port opening. A new planned city, which was different from other traditional areas in terms of appearance, 
was established. With the rapid urbanisation after the opening of the port, the foreign residential area in Gunsan expanded, characterised by 'concession', in which the consul of a specific country grants land to their own citizens, rather than 'settlement', which is a temporary form of residence [23].

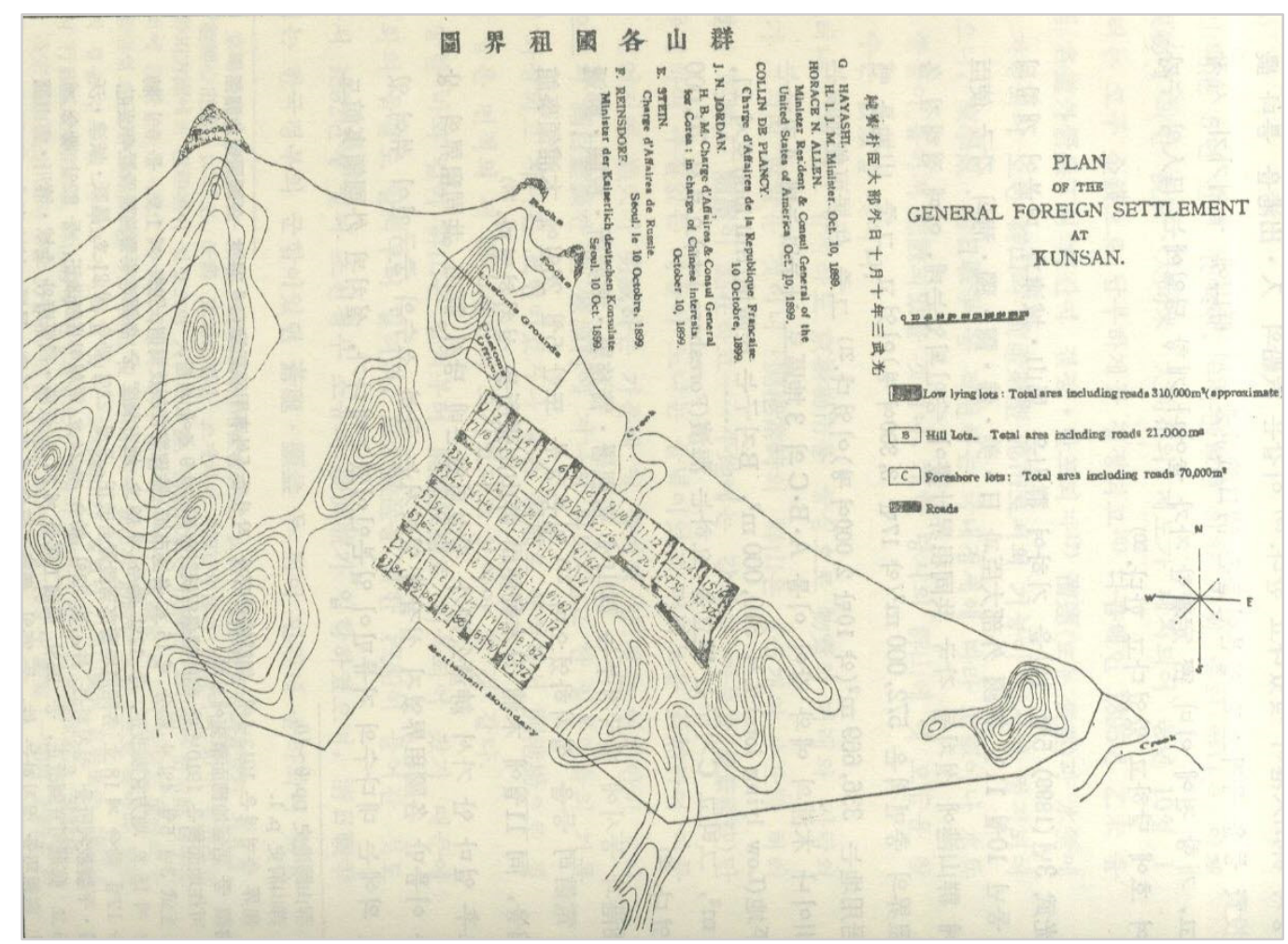

Figure 1. Foreign settlement map in Gunsan, 1899 [22].

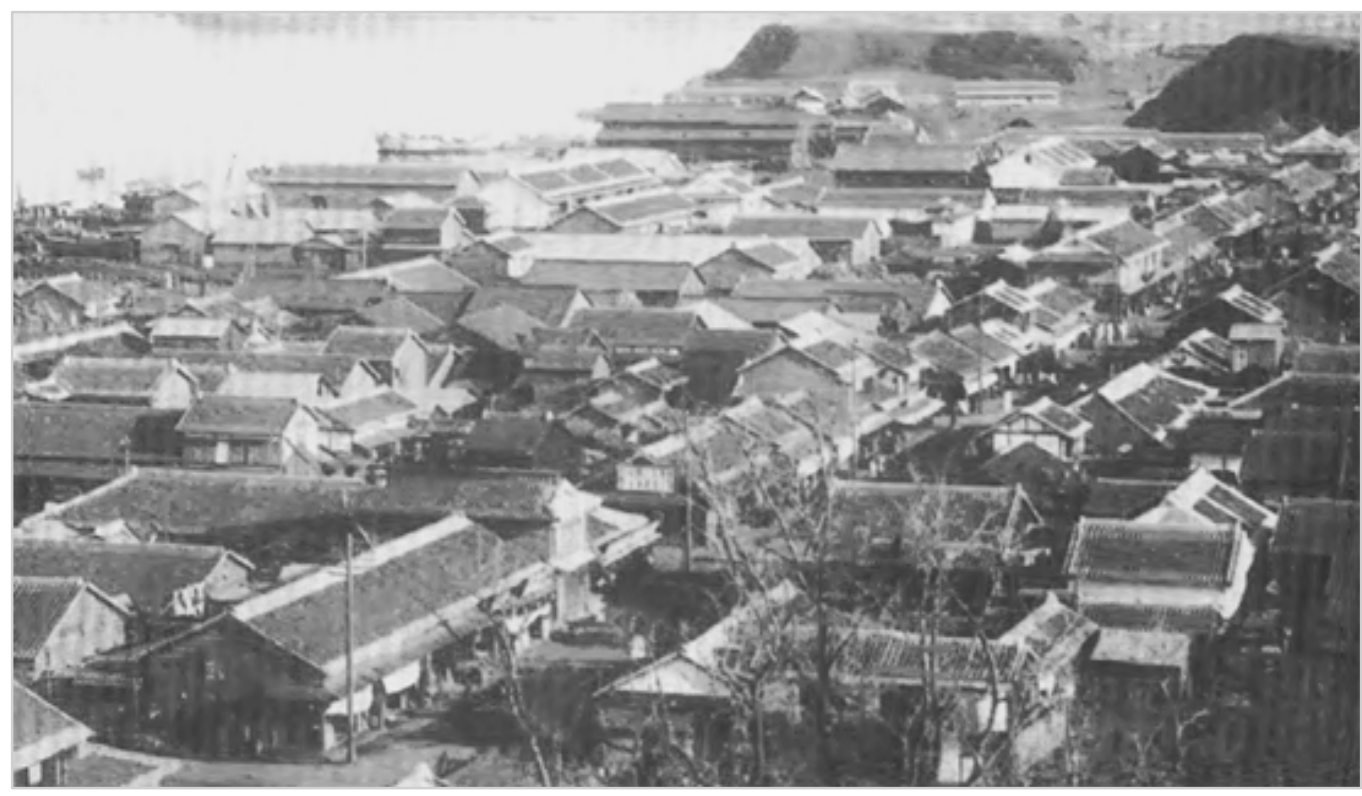

Figure 2. Foreign settlement in Gunsan in the 1920s.

Regarding the economic changes of Gunsan, as rice exports to Japan were the mainstay, the number of exports increased every year from the opening of the port until 1910, when Japan was forced to annex Korea. Specific data on this are presented in Table 1 below. As the amount of rice exported to Japan increased, the port facilities were expanded, such 
that several transport ships could dock at the Gunsan Port simultaneously, and modern transportation facilities, such as maintained roads and railroads for transporting imported and exported goods, were gradually completed [24].

Table 1. Changes in exports after port opening [25].

\begin{tabular}{cccc}
\hline Year & Export Amount & Year & Export Amount \\
\hline 1899 & 8191 & 1905 & 362,911 \\
\hline 1900 & 74,812 & 1906 & 641,255 \\
\hline 1901 & 259,011 & 1907 & $1,917,262$ \\
\hline 1902 & 311,124 & 1908 & $1,833,392$ \\
\hline 1903 & 842,192 & 1909 & $2,049,530$ \\
\hline 1904 & 417,330 & 1910 & $2,210,156$ \\
\hline
\end{tabular}

Table 2 shows that the population of Gunsan increased every year, but there was a dramatic increase between 1902 and 1903. Table 1 shows that the export amount also increased dramatically during the same period, and hence, there is a high correlation between economic factors such as export and population growth. Furthermore, regarding the ratio between Japanese and Koreans, the number of Japanese steadily increased since the opening of the port, and in 1907, it increased to a level close to that of Koreans. Subsequently, there were times when the Japanese outnumbered the Koreans, and accordingly, the proportion of foreigners in Gunsan, mostly Japanese, steadily increased.

Table 2. Increase in Gunsan's population after port opening [25].

\begin{tabular}{ccccc}
\hline Year & Koreans & Japanese & Other Foreigners & Total \\
\hline 1899 & 511 & 77 & 0 & 588 \\
\hline 1900 & 780 & 422 & 24 & 1226 \\
\hline 1901 & 921 & 472 & 56 & 1449 \\
\hline 1902 & 1300 & 569 & 63 & 1932 \\
\hline 1903 & 1811 & 1225 & 78 & 3114 \\
\hline 1904 & 2113 & 1262 & 73 & 3448 \\
\hline 1905 & 3451 & 1620 & 85 & 5156 \\
\hline 1906 & 2835 & 2050 & 96 & 4981 \\
\hline 1907 & 2903 & 2956 & 128 & 5987 \\
\hline 1908 & 1494 & 3060 & 131 & 4685 \\
\hline 1909 & 5466 & 3220 & 96 & 8782 \\
\hline 1910 & 3830 & 3448 & 95 & 7373 \\
\hline
\end{tabular}

From the end of the 19th century to the beginning of the 20th century, the urbanisation of Gunsan was centred on foreign settlements adjacent to the northern port of Gunsan. As the proportion of migrants continuously increased and foreign cultures became involved in the formation of urban culture, this region became more open to cultural diversity and other cultures than other regions were [26]. From 1918 to 1921, facilities for processing, storage, and distribution of rice were expanded around Gunsan Port, which expanded through the construction of the secondary port, and facilities related to rice export were created. Urbanisation caused by the population increase of Gunsan expanded further as the number of government offices such as police offices, courts, customs, post offices, and other commercial facilities increased. In the 1920s, the trade scale of Gunsan increased 70 times compared to when the port was opened in 1897. In addition, with the development of light 
industries such as rice milling, brewing, and fertilizer linked to rice, the population steadily increased, and accordingly, it grew to be a major modern city in Korea [27].

Regarding this expansion of the city, the port function declined as trade with Japan ceased after liberation in 1945, and with the outbreak of the Korean War in 1950, the post-war recovery period continued. Gunsan fell into a long stagnation. Then, in the mid1970s, the development of the Gunsan Port emerged as the construction plan of the coastal industrial complex was promoted in the Gunsan area. Furthermore, the west coast of Korea was developed, as trade with China was revitalised in the 1980s. A large-scale industrial complex and a new port were constructed in Gunsan, and the city was transformed into an industrial city [26].

Although Gunsan was an agricultural city based on the production and trade of agricultural goods such as rice and fertilizer during the colonial period, it transformed into an industrial city after liberation as industrial complexes were built in new urban areas and housing land development was carried out during the industrialisation process of Korea. In this process, the old city region, which was built during the colonial era and had social infrastructure, was excluded from the planning of the new industrial city, and its function declined. As changes in the industrial structure occurred and new towns on the outskirts were developed until the 1980s, there was a phenomenon of decline in the urban centre due to outdated facilities, the decline of commercial functions, and a decrease in population in the old city region, and the port's function also weakened and suffered a sharp decline [28].

\subsection{Modern Cultural City Project for Gunsan's Regeneration}

The main function of the old city region of Gunsan gradually declined because of changes in the industrial structure and times, but this area formed the spatial prototype of the modern city of Gunsan. Buildings and industrial facilities demonstrating the history and regional characteristics of Gunsan are scattered here. In the 2000s, a method was sought for in order to restore local identity to the facilities of the decaying original downtown so they could be utilised as major resources for urban regeneration. This trend was the result of actively accepting the change in times, which required a new approach to urban regeneration related to a reflection on the city's creativity and cultural values and the lives of local residents, unlike the revitalisation that had focused on the physical development of the declining city.

This change of perspective on the city strengthened access to new urban culture with the 'UNESCO Creative Cities Network' promoted by UNESCO in 2002. Sustainable urban development using culture and art as the major means of urban regeneration began to be applied worldwide. In the case of South Korea, urban and regional regeneration projects using various cultural resources were carried out, starting with the Cultural City project in 2004 [29].

A notable project for the development and construction of urban cultural resources in South Korea is the 'Modern Industrial Heritage Cultural Belt' project, which was a contest organised by the Ministry of Culture, Sports, and Tourism in 2008. This was a policy project aimed at revitalising the local economy by building local cultural infrastructure and utilising it as a tourism resource that preserves and manages industrial heritage in order to reclaim it as a space for cultural and artistic creation. Gunsan was selected for this contest, and a project plan was developed that utilises the industrial heritage of the old city region as a cultural space, centring on the Gunsan Inner Port area of the old city region formed during the Japanese colonial period. At the mid- to long-term level, it was able to draw support from the central government for urban regeneration.

The 'Modern Cultural City Creation Project', which was carried out from 2009 to 2019, took place mainly in the Gunsan Inner Port and the old city region (Figure 3). In the first phase of the project, from 2009 to 2013, the Gunsan Inner Port area was selected as a cultural belt district. The Gunsan Modern History Museum was built here and granted the role of a core institution. The former Gunsan branch of Chosun Bank, the former Gunsan branch of Japan's Eighteenth Bank, and the former Gunsan customs main building, which 
were modern industrial remains scattered nearby, were converted and utilised as cultural spaces. In the second phase of the project, from 2014 to 2019, the old city region, which was established as a foreign settlement for foreigners during the port opening period, was selected as a historical landscape district. Trails and scenic routes where visitors could experience history were developed by maintaining and utilising old buildings built in the early 20th century. The focus was also on revitalising the local economy by carrying out a street maintenance project for the further convenience of tourists.

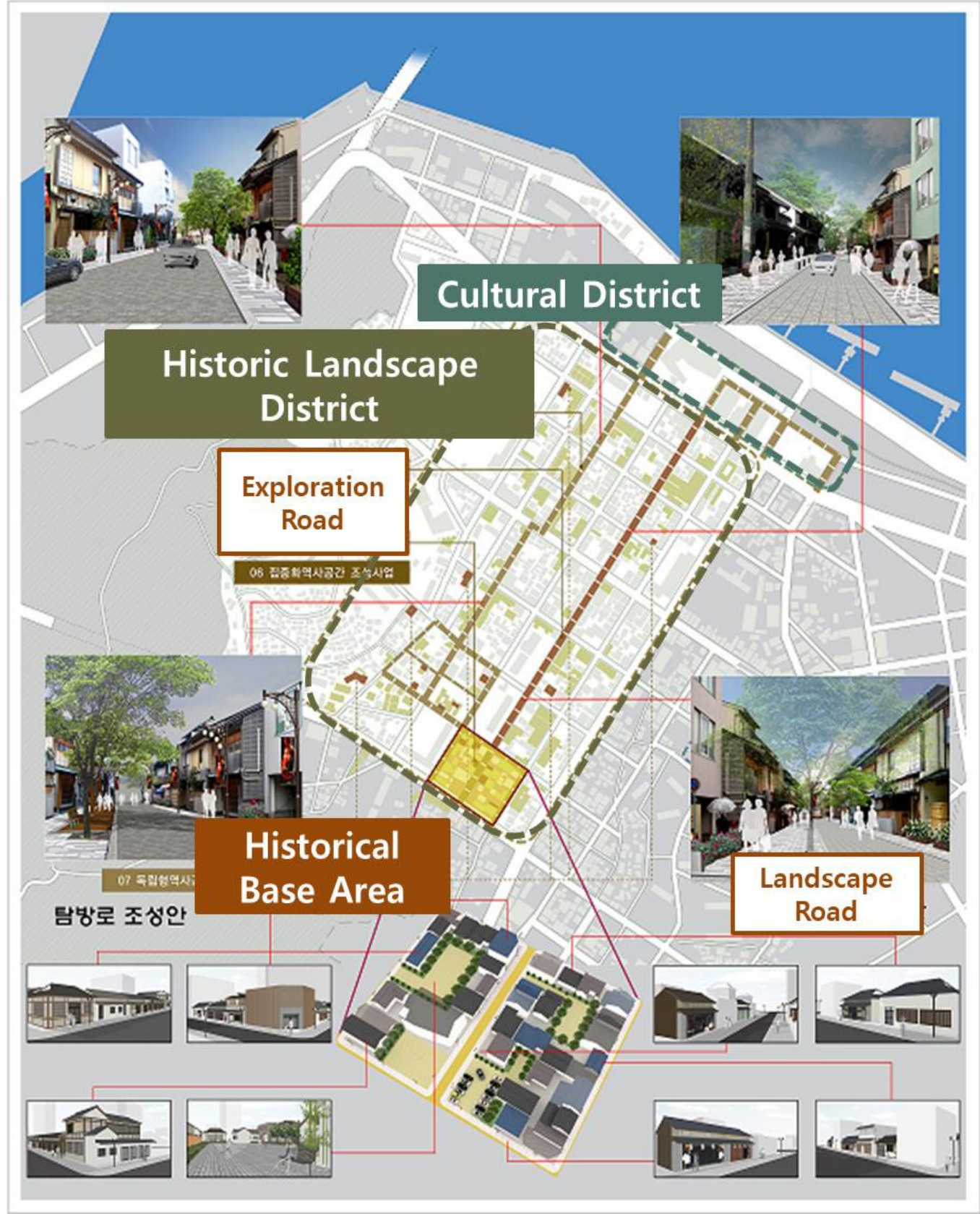

Figure 3. Modern Cultural City Creation Project, 2009-2019 [30].

A series of short-term projects were carried out because of their positive effect on the project, which revitalised the old city region through the preservation and utilisation of modern heritage. Representative examples are the 'Project of Leading Area for Urban Regeneration' (2014-2017) and the 'Urban Regeneration New Deal Project' (2018-2022). These projects were spatially linked with the already established 'Cultural District' and 'Historical Landscape District', creating an experiential space to attract more tourists. By 
purchasing about 40 buildings in an area where Japanese-style buildings were concentrated and utilising the architectural prototype of the Japanese colonial period, this area was set as a centralised area for modern architecture. Accommodation experience centres, which used modern architecture, and commercial facilities providing traditional fermentation experiences and selling folk liquor and traditional tea were intensively fostered.

In addition, the neglected railroad that formed the railroad line at Gunsan Station, which was used to transport rice to the port during the Japanese colonial period, was disconnected because of the deterioration of the port function, and Gunsan Station was moved to another area. A plan to introduce a tram into the inner harbour area of the original city centre using the neglected railroad is being considered. As part of the 'Urban Regeneration New Deal Project', a plan has been developed to use the abandoned railroads as a local specialised resource and to improve tourism vitalisation by networking existing cultural, artistic, and tourism base spaces.

The old downtown of Gunsan seeks and carries out urban changes in terms of tourism vitalisation to create a new urban economy while retaining the appearance of a modern city built in the early 20th century. The fundamental basis of the vitalisation of the old city region of Gunsan is that the old and abandoned modern industrial facilities were evaluated as new urban cultural resources and regeneration policies to mediate local history and new cultural values by using them were continuously implemented.

\subsection{Modern Industrial Heritage as the Site-Specific Resources}

The interpretation of 'place', which is currently rapidly moving away from the literal meaning, is being linked with the signification process related to the region and is actively reviewed in urban regeneration. Modern urban planning is moving away from building a homogeneous city that meets economic and functional requirements with a simple physical space, and is paying attention to site-specificity, which highlights the unique aspects of the history and identity of the region. This perspective, based on the history, suggested a differentiated alternative to the commercial and ideological phenomenon of culture and art by integrating the physical conditions of individual places into the field of culture and art as the part of the production, exhibition, and reception of arts and culture in the late 1960s and early 1970s. The same context led to a reflection on the connection between place and local identity [20].

A place is not a set of actual physical properties of individual locations that make up a city, but a complex structure constructed through social, economic, and cultural processes. It comprises the past and present of the city and affects the experiences of external visitors and the lives of residents. Accordingly, the same components of the city that are homogenised wherever one goes, such as fast-food restaurants, shopping malls, branded stores, and hotels, have no relation to any particular locality. In this same homogenised city, local identity, such as attachment to a place and authenticity, disappear.

Recognising that restoring the deep and symbolic meaning of a place is an important value constituting the identity of the region, the revitalisation focused on Gunsan's original downtown area and paid attention to the preservation and utilisation of abandoned industrial facilities built during the old city formation period. However, Gunsan was built as a colonial city during the Japanese colonial period, and it developed as a trading port for economic and political purposes according to the needs of Japan. Since the modern industrial heritages that currently exist are unique urban resources that show locality and at the same time are also the products of colonial history, which need to be eliminated, there were many controversial aspects in terms of their usage. However, the cultural value of industrial heritages was recognised, and a social consensus was reached which decided that the most effective way to creatively build the regional character of Gunsan was to use it. Thus, cultural utilisation using the placeness of industrial heritage was actively carried out.

Modern industrial facilities scattered around the old Gunsan Port retain the history of Gunsan and the early urban landscape of Gunsan when it was formed as a port city. 
Hence, these facilities have strong characteristics of the site-specific resources that show the uniqueness of the region. Such industrial facilities were utilised as a cultural space through the 'Modern Cultural City Creation' project, enhancing the value of industrial heritage and serving as the infrastructure for urban revitalisation. Representative cases and outlines are summarised in Figure 4.

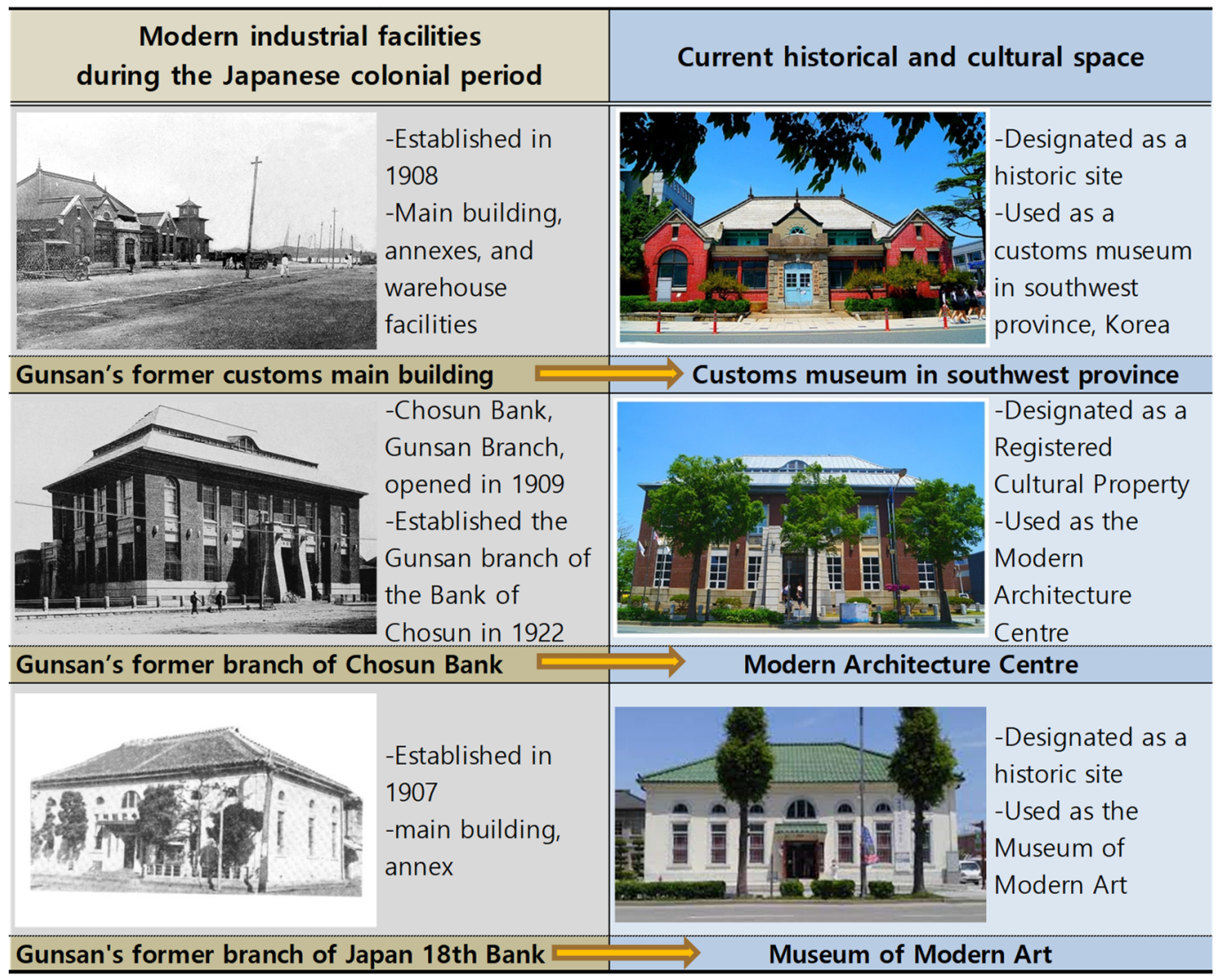

Figure 4. Site-specific resources used as museum spaces in Gunsan.

By using site-specific resources, which preserve the uniqueness and historicity of modern industrial heritage as much as possible and represent locality as cultural institutions, Gunsan transformed into a site of regionally specialised cultural heritage. It transformed the declining old city region into a representative 'modern cultural city'. The site-specificity applied to the old city region focused on the history and characteristics of the specific period in which the urban space was formed, and the site characteristics of this formed the foundation to settle as a public memory.

Moreover, as outlined in Figure 5, there are cases in which the modern buildings of the old downtown, built for various purposes, are being used as infrastructure for artistic creation or a complex cultural space in the form of a program. These notable cases demonstrate how site-specific cultural resources can increase the cultural enjoyment of local artists and local people.

Activation strategy, which focuses on specific points in history and local characteristics through places, is effective in linking places and memories. Regarding the series of projects centred on the old downtown of Gunsan, new experiences are being accumulated through cultural use based on the historical memory of the place. They are converted into a new public experience of the area, and they further contribute to the reproduction of social memory [31]. 


\section{Restored modern buildings used as a complex cultural space}

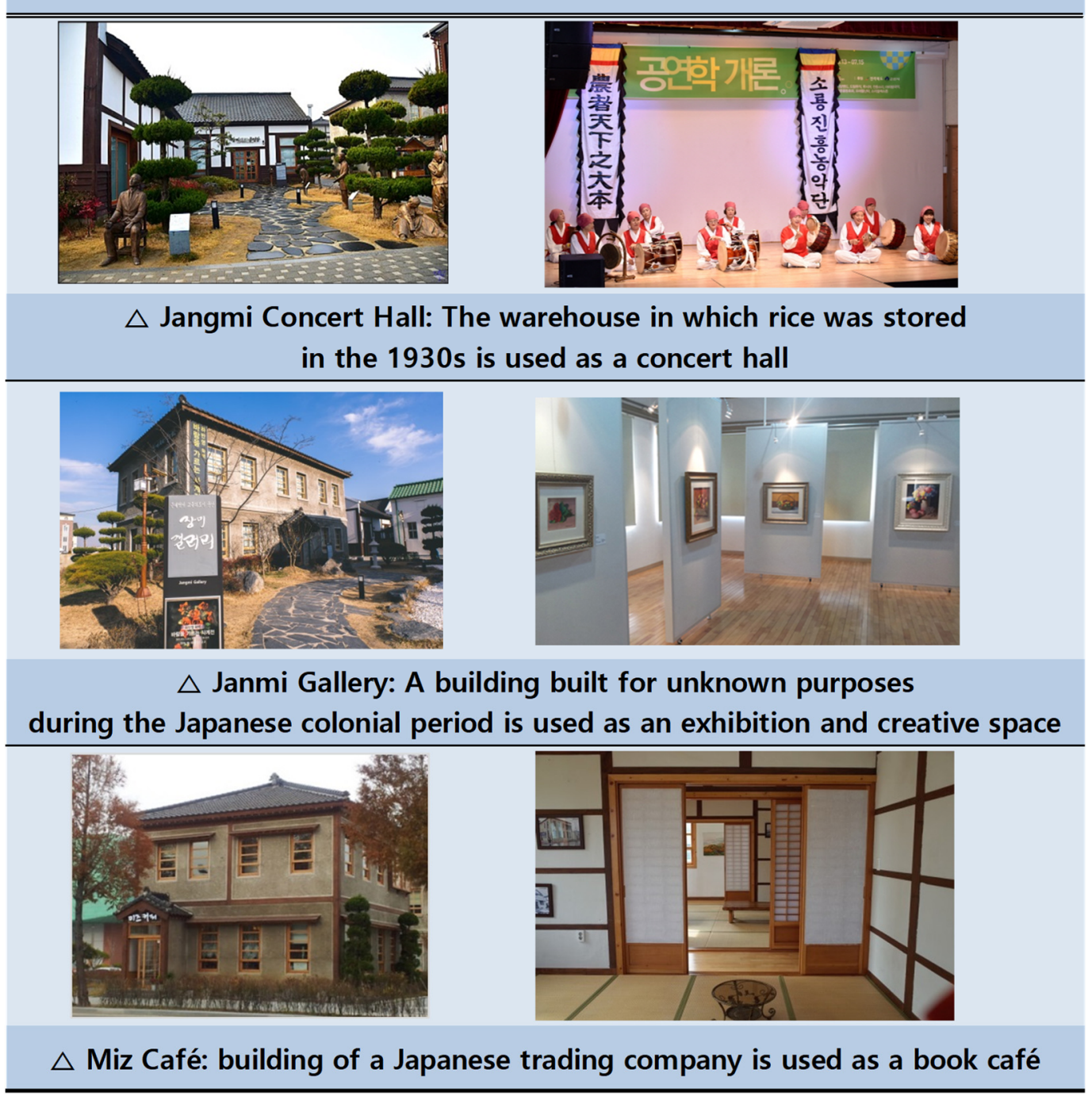

Figure 5. Site-specific resources used as complex cultural spaces in Gunsan.

\section{Discussion}

The regeneration of the old city region of Gunsan was carried out based on a typical government-led project through the support of the central government and the collaboration of local governments. The policy aimed to revitalise the declining old city centre to create related jobs, improve the living environment in underdeveloped areas, and lead social cohesion. It was adjusted and promoted systematically. Gunsan City promotes its mid- to long-term urban regeneration policy in three main directions. The key points are as follows [32]:

1. Establishment of a new economic foundation centred on the old city centre: Create income and jobs for local residents by building a new economic foundation centred on history, culture, and tourism using Gunsan Inner Port, abandoned railroads, and modern cultural assets.

2. Balanced development between new and old cities: Improve the residential environment in declining areas and simultaneously maintain the population or secure a base for inflow by securing a certain level of quality of life in existing urban areas.

3. Strengthening regional innovation capabilities to overcome crises: Strengthen the foundation and capacity for regional innovation by activating cooperative governance 
among local community actors, such as the administration, universities, corporations, civic groups, and residents.

What is noteworthy about the three directions of urban regeneration policy mentioned above is that local residents are included as the ultimate beneficiaries of regeneration, and various local actors have proposed regional development through cooperative governance for sustainable cultural regeneration. When Gunsan's cultural regeneration vision was presented, local residents welcomed the community-friendly policy direction, more than anyone else, and had high expectations for the city in the future.

The positive outcome of the policy was that the old city region was not to be approached simply from the perspective of urban management and maintenance. It discovered cultural and heritage values by using abandoned modern industrial facilities and developed regional characteristics and identities as a 'cultural district' and 'historical landscape district'. Gunsan, which was an old port city during the Japanese colonial period, transformed its image into that of a new city that is a 'modern historical and cultural city'. It became lively, centring on the shopping districts of the old city region because of the influx of tourists. In this respect, the goal of the aforementioned item 1 of the urban regeneration policy was partially achieved, but as a result, the number of commercial facilities in the original downtown are rapidly increasing rather than revitalisation that leads to income and job creation for local residents. Therefore, the revitalisation of the local economy does not lead to the actual results felt by the residents.

In addition, government-led projects are performance-oriented, seeking to achieve policy outcome within a short period, and as a result, problems are constantly faced. In the case of Gunsan, the foundation for revitalisation has been established with a focus on tourism policy to revitalise the local economy, and the focus is on revitalising the local economy through tourism income. Thus, the use of the city's historicity and culture is focused on the hardware aspect of building restoration and conversion to a cultural space, and programs that would attract continuous return visits are lacking. For example, the cultural spaces using modern industrial facilities presented in Figure 4 are aimed at improving the quality of public space and of adjacent residential living conditions, as well as strengthening the tourist-recreational and cultural functions of the area. In practice, however, cultural contents such as various exhibitions, convergence programs, and community-based cultural activities to achieve the purposes of these cultural spaces are not being implemented. Each cultural space is just maintained with a minimum number of operating staffs; in addition, there is no actual agent to solve the problems due to the lack of central management teams in charge of continuous programs, visitor attraction, and group promotions.

Furthermore, as a strategy for urban competitiveness and as a way to restore the industrial heritage of the old downtown as a government-led project, the tourism policy was mainly promoted to draw out short-term results for external tourists. The high degree of dependence on government-led projects and the fragmentary and uniform approach to modern heritage to achieve business results in a short period reveal the limitations of regeneration centred on commercial spaces that are not related to Gunsan's historicity and regional characteristics. Even though it is needed to overcome the limitations of local history and conditions in order to enter to new development trajectory in some points, there are many residents who raise the issue of spending public funding on commercial spaces in the historical and cultural district. It is clear that the balance of commercial facilities in the historical and cultural district representing the local-specific characteristics of Gunsan is a continuous task that needs to be adjusted in the context of future development.

Museum spaces using site-specific resources are focused on the hardware aspect and are operated in the absence of various programs and planning ability. These museum spaces are unable to present various cultural contents other than the permanent exhibitions set at the time of opening, and attractions to motivate visitors into return visits are obviously lacking.

The target group for the revitalisation of the local economy is mainly external tourists, and urban infrastructure focusing on this has been established. Accordingly, public funds 
are being invested in the expansion of commercial spaces, focusing on external tourists rather than the living spaces of local residents. As the number of tourists increased, the old city region came to life, but there were areas wherein the number of local people moving out increased because of rising land prices and rents, despite the fact that they should be the biggest beneficiaries. Another side effect of rapid commercialisation was the so-called tourification, in which the living space of local residents becomes a tourist destination, and the quality of the residential environment deteriorates. This problem was pointed out as an issue to be remedied by Gunsan [33].

The historical and cultural resources of Gunsan are not separated from the living space of the residents and they are located adjacent to each other. Hence, the regeneration policy, which aims at tourist-centred external demand, inevitably leads to the expansion of commercial space. In such an urban environment, the living space of residents becomes the object of tourists' gaze. Accordingly, the direct beneficiaries of the revitalisation felt by the residents are clearly different from the government-led policy performance. Therefore, in order to revitalise an area without marginalising local residents, the continuity of the residential environment of local residents should be considered, and place-making that reflects the experiences and participation of local residents and contains the meaning and identity of their concrete lives should be created.

By using and talking about places, people form attachments to them. The geographer Yi-Fu Tuan coined the term topophilia (literally place-love) to refer to this type of positive identity, a concept that describes how people's sense of who they are, and which larger communities they belong to, is rooted in place. People also have functional relations to places, where they rely on a specific place for social, economic, or cultural support [16].

A series of projects to strengthen the city's creativity and regional revitalisation through the site-specific culture in Gunsan have been constructed as a cultural and historical district by fusing the historical and local characteristics into the unique place. This change of Gunsan has led to its a strong character as an urban village with diversity that converts the industrial facilities into cultural resources and embraces the living spaces where the lives of residents are buried, rather than a megacity composed of skyscrapers and commercial facilities.

There is no doubt that a city's growth strategy is an important factor in sustainable cultural regeneration, but it is necessary to listen to the voices of local residents' concerns about excessive commercialisation that deepens social polarisation and dismantles local communities. In Gunsan, there are various actors such as universities, local business start-ups, civic groups, local experts, residents, and administrators, that share interests and a common vision culture will contribute to creative regional development. Based on this common understanding, the government-led, top-down regeneration policy requires a bottom-up mediation process that promotes communication and participation among various stakeholders in the region, which can be implemented through governance that leads to organic cooperation.

\section{Conclusions}

Jane Jacobs focused on the creativity of cities and emphasised the relationship between the creative transformation of the urban economy and the resulting urban infrastructure. She presented an insight on cities. For her, it was not the hardware reinforcement of the skyscraper that revitalises the city, but neighbourhoods, streets, shops, and the people who live therein that make up a diverse and sustainable urban ecosystem [19].

She considered the value of the alleyway as a diverse building, a street one wants to walk on, and a safe and fun place. Meeting the locals who have made a living there in the alleyway sometimes makes the area more attractive. A visitor can experience the cultural value of a region in the small and insignificant daily life of the region. A private anchor store in an area in which residents coexist can serve as an important mediating space. Representative examples are bakeries, coffee shops, independent bookstores, and guesthouses. Hence, establishing a cooperative relationship with the nearby Kunsan National 
University or the growth of an intermediary group, such as a local creator community, is also important.

The original downtown of Gunsan has been transformed into a historical and cultural district that embodies cultural values. Such a cultural space can strengthen the creative capacity of local communities through mediating activities such as local community programs, community art education, and art workshops. In Gunsan, interest in alley commercial districts where visitors can experience the uniqueness and diversity of the region is just gradually increasing. The importance of small shops in downtown alleys is being emphasised because of their mediation function that constitutes the daily life and lifestyle of the region as a place of communication with local residents, as well as their suitability as places where tourists can experience the authenticity of the region.

So far, all regions have been competing to attract national industries, and a comprehensive industry model works. However, there is need for more locality-specific, bottom-up and endogenous development efforts in the post-industrial phase of development. In other words, the unique industry of the region is a virtuous cycle in the region, and the value of the economy of the living area cannot be ignored. Rather than the homogeneous model applied in the government-led, top-down policy, a new leap forward for urban creative development, which reflects the individuality and diversity of the region, is needed in the case of Gunsan. It is necessary to further reflect on how to create various public goods in the urban economy, such as support for social enterprises to revitalise local commercial areas, the development of local currency, and community-friendly urban infrastructures.

Several implications can be drawn from the cultural regeneration of Gunsan utilising modern industrial heritage (Figure 6).

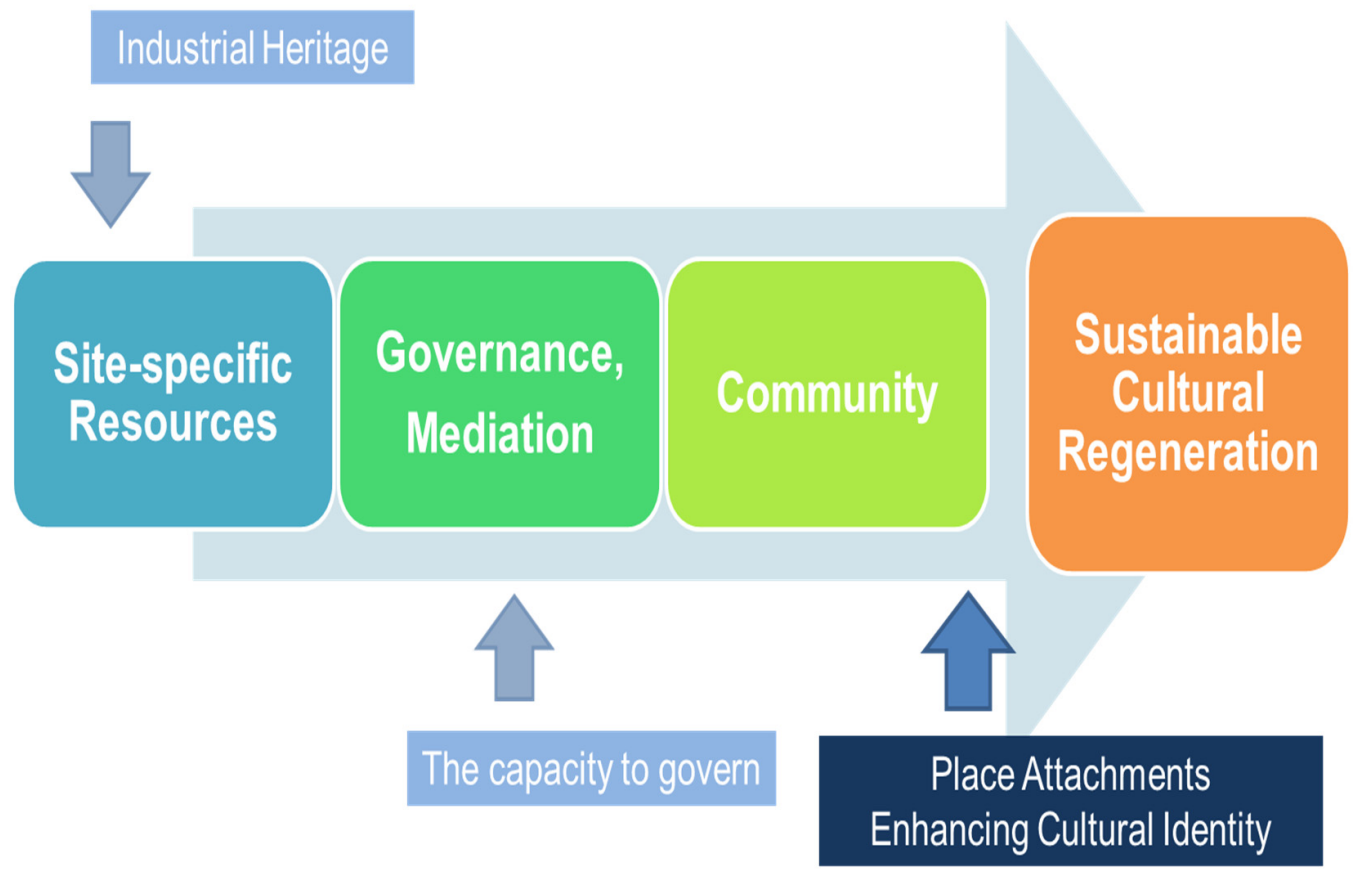

Figure 6. Sustainable cultural rurban regeneration in Gunsan.

By moving away from the facility-centred perspective that uses a fragmentary approach from the government-led, performance-oriented project aspect, the cultural value of modern industrial heritage that drives urban revitalisation was verified. Using this, a multi-layered approach that uses the base place to embody the historicity and identity of the region was attempted. In this respect, there were positive effects. However, government-led projects are performance-oriented to achieve policy outcomes in a short period of time, and as a result, they constantly face problems. From a more long-term 
perspective, it is important to establish integrated management teams to continuously and stably operate the cultural spaces in the historical and cultural district.

Aspects of 'living heritage', wherein modern industrial heritage is not separated from the lives of local residents and can agrow and change in response to various demands and changes in the times, are needed in order to regenerate a sustainable city. Such sustainability requires various cultural mediation activities and a mediator. Sustainable urban regeneration can be achieved when these mediating activities are undertaken with a focus on the local community.

The cultural urban regeneration of Gunsan is a process of achieving the creativity of the region and community self-reliance through culture, and there is still room for development. The history of colonialism, corresponding rapid social changes, and rapid urban expansion through compressed growth is a historical context shared by major Asian cities. Therefore, if comparative studies on cultural regeneration using industrial heritage are conducted in a more macroscopic Asian context, more integrated and in-depth results on cultural regeneration can be derived.

Author Contributions: Conceptualization, H.C. and J.L.; methodology, H.C.; validation, H.C. formal analysis, H.C.; writing-original draft preparation, H.C.; writing-review and editing, J.L.; supervision, J.L.; project administration, J.L.; funding acquisition, J.L. All authors have read and agreed to the published version of the manuscript.

Funding: This research was funded by the Hankuk University of Foreign Studies Research Fund.

Conflicts of Interest: The authors declare no conflict of interest.

\section{References}

1. Kang, D.J. Exploring a Definition of Urban Heritage with focus on Urban Regeneration. J. Korea Plan. Assoc. $2013,4,254$.

2. Kim, S.H. Resuscitation of the colonial town and the creation of new communication: Focusing on Gunsan. J. North-East Asian Cult. 2013, 36, 6-7.

3. Jung, S. The Modern and Post-modern of Modern Cultural Heritage. Asian Comp. Folk. 2020, 72, $130-131$.

4. TICCIH. The Nizhny Tagil Charter for the Industrial Heritage. In Proceedings of the TICCIH XII International Congress, Moscow, Russia, 17 July 2003; pp. 169-175. Available online: https://www.icomos.org/18thapril/2006/nizhny-tagil-charter-e.pdf (accessed on 30 August 2021).

5. Kim, H.C. A Critical Review on the Conceptual Scope and Policy Institution Process in the Korean Context of Korean Urban Regeneration. J. Korean Urban Manag. Assoc. 2013, 26, 5.

6. Landry, C. The Creative City: A Toolkit for Urban Innovators; Earthscan Publications: London, UK, 2000.

7. Florida, R. Cities and the Creative Class; Routledge: New York, NY, USA, 2005.

8. Mommaas, H. Cultural Clusters and the Post-industrial City: Towards the Remapping of Urban Cultural Policy. Urban Stud. 2004, 41, 507-532. [CrossRef]

9. Paddison, R.; Hutton, T. Cities and Economic Change: Restructuring and Dislocation in the Global Metropolis; Paddison, R., Hutton, T., Eds.; Sage: London, UK, 2014; pp. 1-12.

10. Jucu, I.S. Rebranding the cultural legacy of communism: The golden stag festival(Braşov, Romania) and local placemaking. J. Balk. Near East. Stud. 2020, 22, 478-482. [CrossRef]

11. Evans, G.; Shaw, P. The Contribution of Culture to Regeneration in the UK: A Report to the DCMS; London Metropolitan University: London, UK, 2004; pp. 4-5.

12. Chung, H.K.; Lee, J.O. Community Cultural Resources as Sustainable Development Enablers: A Case Study on Bukjeong Village in Korea compared with Naoshima Island in Japan. Sustainability 2019, 11, 1405. [CrossRef]

13. Baik, S.; La, D.S. A Study on the Projects of Making a Region through the Arts; Seoul Development Institute: Seoul, Korea, 2008 ; p. 3.

14. Brundtland, G.H. Report of the World Commission on Environment and Development: Our Common Future; United Nations: New York, NY, USA, 1987; p. 16.

15. Rogers, P. Conservation and implementation. In Conservation of Buildings in Developing Countries; Zetter, R., Ed.; Oxford Polytechnic: London, UK, 1982; p. 15.

16. Jaffe, R.; De Koning, A. Introducing Urban Anthropology; Routledge: New York, NY, USA, 2016; pp. $24-25$.

17. Relph, E. Place and Placelessness; Nonhyung: Seoul, Korea, 2005; p. 13.

18. Zukin, S. Changing Landscapes of Power: Opulence and the Urge for Authenticity. Int. J. Urban Reg. Res. 2009, 33, 543-553. [CrossRef]

19. Jacobs, J. The Death and Life of Great American Cities; Kang-eun, Y., Translator; Random House: New York, NY, USA; Greenbee Books: Seoul, Korea, 2010; pp. 325-421.

20. Kwon, M.W. One Place after Another: Site-Specific Art and Locational Identity; The MIT Press: Cambridge, MA, USA, $2002 ;$ pp. 13-14. 
21. Youn, J.S. A Geographical Study on the Process of Modern City Forming as Opening Port: A Case Study of Kunsan. J. Korean Geogr. Soc. 1985, 20, 74.

22. Son, J.M. A Study on the Urban Change Process during the Port Opening Period in Korea; Iljisa: Seoul, Korea, $1982 ;$ p. 304.

23. Lee, H.J. A Study on Korean Open Port; Iljogak: Seoul, Korea, 1975; pp. 157-160.

24. Song, S.K. Present status of architectural heritage and architectural characteristics of the modern city of Gunsan during the Japanese colonial period. In Proceedings of the Presentation Book for Korean Society for Local History and Culture, Seoul, Korea, 20 November 2004; Booklet Publishing History and Culture Society: Seoul, Korea, 2004; pp. 130-131.

25. Gunsan Department. History of Gunsan City; 1935; pp. 19, 191-192.

26. Kim, Y.J.; So, S.Y.; Lee, J.D.; Lee, S.H. The Formation and Transformation of the Modern Port City, Kunsan: Space, Economy and Culture; Book Publishing Hanul: Paju, Korea, 2006; pp. 146, 272.

27. Kim, H.S. Gunsan Modern Urban Architecture Cultural Heritage and Urban Regeneration. Urban Plan. $2015,2,26$.

28. Oh, E.J. A Study on Cultural Urban Regeneration Plans for Preserving the Historicity of Modern Industrial Heritage. Master's Thesis, Hankuk University of Foreign Studies, Seoul, Korea, 2019; p. 31.

29. Kim, H.J. Urban regeneration strategy using cultural contents. Plan. Policy 2014, 4, 43.

30. Gunsan Modern History Museum, Archive Materials. Available online: https://museum.gunsan.go.kr/content/sub03/03_06 (accessed on 30 August 2021).

31. Cresswell, T. PLACE: A Short Introduction; Sigma Press Inc.: Seoul, Korea, 2012; pp. 132-135.

32. Gunsan City, Introduction of Urban Regeneration Project. Available online: https://www.gunsan.go.kr/main/m432 (accessed on 30 August 2021).

33. Yu, A.R.; Pak, S. Change of Original Downtown in Gunsan through Urban Regeneration Project: Change of Space \& Occupants focused on the Main Streets of Modern History-Culture Belt Project. J. Reg. Assoc. Archit. Inst. Korea 2015, 17, 10-11. 